\title{
Effect of indium doping on zinc oxide films prepared by chemical spray pyrolysis technique
}

\author{
GIRJESH SINGH*, S B SHRIVASTAVA, DEEPTI JAIN ${ }^{\dagger}$, SWATI PANDYA ${ }^{\dagger}$, \\ T SHRIPATHI ${ }^{\dagger}$ and $V$ GANESAN ${ }^{\dagger}$ \\ School of Studies in Physics, Vikram University, Ujjain 456 010, India \\ ${ }^{\dagger}$ UGC-DAE-Consortium for Scientific Research, Khandwa Road, Indore 452 017, India
}

MS received 13 March 2009; revised 2 March 2010

\begin{abstract}
We report the conducting and transparent In doped $\mathrm{ZnO}$ films fabricated by a homemade chemical spray pyrolysis system (CSPT). The effect of In concentration on the structural, morphological, electrical and optical properties have been studied. These films are found to show $(002)$ preferential growth at low indium concentrations. An increase in In concentration causes a decrease in crystalline quality of films as confirmed by X-ray diffraction technique which leads to the introduction of defects in $\mathrm{ZnO}$. Indium doping also significantly increased the electron concentrations, making the films heavily $\boldsymbol{n}$ type. However, the crystallinity and surface roughness of the films decreases with increase in indium doping content likely as a result of the formation of smaller grain size, which is clearly displayed in AFM images. Typical optical transmittance values in the order of $(80 \%)$ were obtained for all films. The lowest resistivity value of $0.045 \Omega-m$ was obtained for film with $5 \%$ indium doping.
\end{abstract}

Keywords. ZnO; $\mathrm{ZnO}:$ In; chemical spray pyrolysis technique.

\section{Introduction}

Recently there has been a great interest in the investigation of transparent conducting oxides (TCOs). Among them, $\mathrm{ZnO}$ is particularly more interesting as it has strong applications in optoelectronics devices owing to its direct bandgap $\left(E_{\mathrm{g}} \sim 3.3 \mathrm{eV}\right)$ at $300 \mathrm{~K}$. $\mathrm{ZnO}$ is also found to have other strong applications such as fabrication of electronic devices, transparent thin film transistor, where the protective covering preventing light exposure is eliminated since $\mathrm{ZnO}$ based transistors are insensitive to visible light. As a matter of fact, simultaneous occurrence of both high optical transmittance in the visible range, and low resistivity make $\mathrm{ZnO}$ an important material in the manufacture of heat mirror used in gas stoves, conductive coating in aircrafts glass avoiding surface icing, and as thin film electrode in amorphous silicon solar cells. By controlling the doping level electrical properties can be changed from insulator through $n$-type semiconductor to metal while maintaining optical transparency that makes it useful for transparent electrodes in flat panel displays and solar cells (Ozgur et al 2005). $n$-Type doping of $\mathrm{ZnO}$ is relatively easy as compared to $p$-type doping. Group III elements like Al, Ga and In can be used as $n$-type dopant (Kato et al 2002). Doping with Al, Ga and In has been attempted by many groups, resulting in high quality,

*Author for correspondence (girijesh.s@gmail.com) highly conducting $n$-type $\mathrm{ZnO}$ thin films (Minami et al 1984; Ataev et al 1995; Myong et al 1997; Ko et al 2000; Chen et al 2001; Assuncao et al 2003; Liu et al 2003). Among group III element much of the work has been done by using $\mathrm{Al}$ as a dopant because the ionic radius of $\mathrm{Al}$ is smaller than that of In and Ga. However, thermodynamic data show that the free energy of formation of $\mathrm{Al}_{2} \mathrm{O}_{3}$ is lower than that of $\mathrm{ZnO}$, suggesting that $\mathrm{Al}_{2} \mathrm{O}_{3}$ has very high reactivity with oxygen. In this regard, indium is an attractive dopant for $n$-type $\mathrm{ZnO}$, as it has less reactivity and greater resistivity to oxidation relative to Al. So far there have been few reports on indium doped $\mathrm{ZnO}$ thin films. Cao et al (2006) prepared indium doped $\mathrm{ZnO}$ films by rf sputtering method and obtained film with a minimum resistivity and maximum crystalline size. Kim et al (2007) deposited $\mathrm{ZnO}$ thin film by rf magnetron sputtering. They investigated the effect of indium doping on the structural and electrical properties of the fabricated film.

Numerous thin film deposition techniques have been employed by different workers e.g. chemical vapour deposition (CVD) (Ataev et al 1999), radio frequency magnetron sputtering (Song et al 2002), sol-gel process (Lee et al 2003), pulsed laser deposition (Singh et al 2001), electrodeposition (Cembrero et al 2004) and spray pyrolysis (Ma and Lee 2000; Lee and Park 2004) for the preparation of undoped and doped $\mathrm{ZnO}$ films. Among these techniques CSPT has many advantages; it is easy, 
inexpensive, and well adapted for mass fabrication. In this paper, we report the results of our investigation of IZO at different doping concentrations. In the present work, all films have been prepared by using CSPT. We have particularly studied the structural, morphological, electrical and optical properties of IZO films deposited onto glass substrate at a temperature of $380 \pm 5^{\circ} \mathrm{C}$.

\section{Experimental}

Undoped $\mathrm{ZnO}$ and indium doped $\mathrm{ZnO}$ thin films at different dopant percentages were deposited by CSPT (Godbole et al 2007). This technique is most suitable for the deposition of oxide films. Aqueous solution of $\mathrm{Zn}\left(\mathrm{NO}_{3}\right)_{2} \cdot 6 \mathrm{H}_{2} \mathrm{O}$ $(0.05 \mathrm{M})$ was used for spraying. Doping was achieved by the addition of indium trichloride to the precursor solution, and the whole mixture was sprayed onto the microscopic glass slides. The concentration of In was varied at $1-5 \%$ in the initial solution. Dry air was used as a carrier gas and the spray rate of the solution was $1 \mathrm{~cm}^{2} / \mathrm{min}$. The temperature of the substrate was maintained at $380 \pm 5^{\circ} \mathrm{C}$ and monitored by a chromel-alumel thermocouple close to the substrates. All deposition parameters were optimized.

The characterization of the prepared film was carried out by Rigaku X-ray diffractometer using $\mathrm{Cu}-\mathrm{K} \alpha$ radiation having wavelength, $1.5418 \AA$. The morphological studies were done by using AFM (Digital instruments Nanoscope-IV, with $\mathrm{Si}_{3} \mathrm{~N}_{4} 100 \mathrm{~nm}$ cantilever, $0.58 \mathrm{~N} / \mathrm{m}$ force constant) measurements in contact mode. The resistivity measurements were done using Keithley 617 programmable electrometer in association with Lakeshore temperature controller in a homemade set-up with Teflon insulated shielded coaxial cables. The optical measurements were done by means of UV-Vis spectrophotometer (Perkin Elmer Lambda 950).

\section{Results and discussion}

\subsection{Structural studies}

The X-ray diffraction spectra of IZO films deposited at $380^{\circ} \mathrm{C}$ for various dopant concentrations are shown in figure 1. Undoped $\mathrm{ZnO}$ film shows a preferential orientation along the $\left(\begin{array}{lll}0 & 0 & 2\end{array}\right)$ plane at $2 \theta=34 \cdot 3^{\circ}$. The other peaks observed in the X-ray diffractogram are $\left(\begin{array}{lll}1 & 0 & 2\end{array}\right),\left(\begin{array}{lll}1 & 1 & 0\end{array}\right)$ and (llll $\left.\begin{array}{lll}0 & 3\end{array}\right)$, but intensity of these peaks are found to be too less as compared to the preferentially oriented peak. The $2 \theta$ values were compared with the standard JCPDS data card (80-0075). With the increase in indium doping percentage, the intensity of the peak corresponding to the plane $\left(\begin{array}{lll}0 & 0 & 2\end{array}\right)$ is found to decrease and that corresponding to $\left(\begin{array}{lll}1 & 0 & 1\end{array}\right)$ and $\left(\begin{array}{lll}1 & 0 & 0\end{array}\right)$ plane increase. Similar behaviour has been reported by other workers (Goyal et al 1993; Delgado et al 2000; Yoshida et al 2000). The results of
IZO allow us to state that there is a predominant growth of $\mathrm{ZnO}$ microcrystal with the $c$-axis tilted around 58 degree towards the plane of substrate at higher doping while for lightly doped samples $c$-axis is perpendicular to the plane of the substrate (Major et al 1986). For obtaining the quantitative information concerning the preferential crystalline orientation, texture coefficient $T C$ along (ll $\left.\begin{array}{ll}0 & 2\end{array}\right)$ plane has been calculated (Barret and Massalski 1980) by using the relation

$$
T C(h k l)=\frac{\frac{I(h k l)}{I_{0}(h k l)}}{\sum_{n} \frac{I(h k l)}{I_{0}(h k l)}} \times 100 \%,
$$

where $I(h k l)$ is the measured relative intensity of a plane $(h k l)$ and $I_{0}(h k l)$ the standard intensity of the plane $(h k l)$ taken from the JCPDS data. The value, $T C(h k l)=1$, represents the film with randomly oriented crystallites, while higher value indicates the abundance of grains oriented along $\left(\begin{array}{lll}0 & 0 & 2\end{array}\right)$ direction. The variations of $T C$ for IZO at different In concentrations are presented in table 1. The highest $T C$ value has been found for undoped $\mathrm{ZnO}$ film, as we increase the doping concentration, value of $T C$ goes down showing randomly oriented crystallites. The crystallite size of the film was calculated by the Debye-Scherrer formula, showing a decreasing trend with the increase in In doping concentrations. The lattice parameter $c$ summarized in table 1 slightly increases with

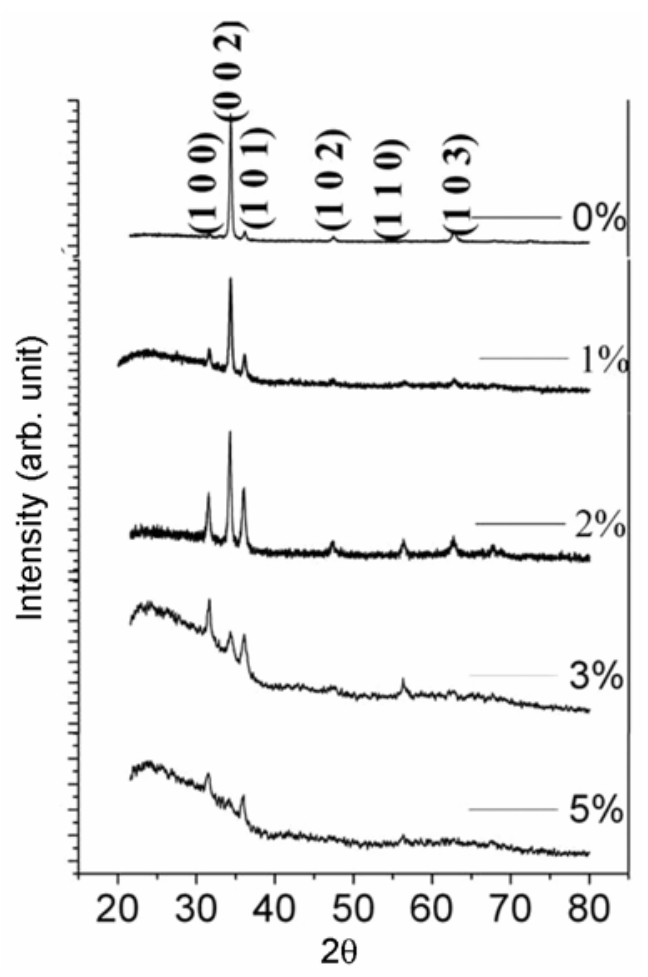

Figure 1. XRD spectra of undoped and indium doped $\mathrm{ZnO}$ films. 
Table 1. Values of lattice constant, texture coefficient, grain size, roughness, optical bandgap and resistivity of IZO film deposited at $380^{\circ} \mathrm{C}$ at various indium dopant concentrations.

\begin{tabular}{|c|c|c|c|c|c|c|}
\hline $\begin{array}{l}\text { Indium } \\
\text { concentration }(\%)\end{array}$ & $\begin{array}{c}\text { Lattice } \\
\text { constant (C) }\end{array}$ & $\begin{array}{l}\text { Texture coefficient } \\
\text { (TC) }\left(\begin{array}{lll}0 & 0 & 2\end{array}\right)\end{array}$ & $\begin{array}{l}\text { Grain size } \\
\quad(\mathrm{nm})\end{array}$ & $\begin{array}{l}\text { Roughness } \\
\text { (nm) }\end{array}$ & $\begin{array}{l}\text { Optical bandgap } \\
\left(E_{\mathrm{g}}\right)(\mathrm{eV})\end{array}$ & $\begin{array}{l}\text { Resistivity } \\
\quad(\Omega-\mathrm{m})\end{array}$ \\
\hline 0 & $5 \cdot 2066$ & 0.951 & 86.59 & $13 \cdot 01$ & $3 \cdot 26$ & $2.8 \times 10^{3}$ \\
\hline 1 & $5 \cdot 224$ & $0 \cdot 661$ & $156 \cdot 36$ & $7 \cdot 010$ & $3 \cdot 28$ & 0.537 \\
\hline 2 & $5 \cdot 225$ & 0.597 & $131 \cdot 24$ & 4.665 & 3.93 & 0.229 \\
\hline 3 & 5.653 & 0.414 & $128 \cdot 32$ & 4.536 & 3.93 & 0.226 \\
\hline 4 & - & - & $126 \cdot 87$ & 2.462 & 3.93 & 0.047 \\
\hline 5 & 5.628 & - & $112 \cdot 23$ & 1.914 & 3.95 & 0.045 \\
\hline
\end{tabular}
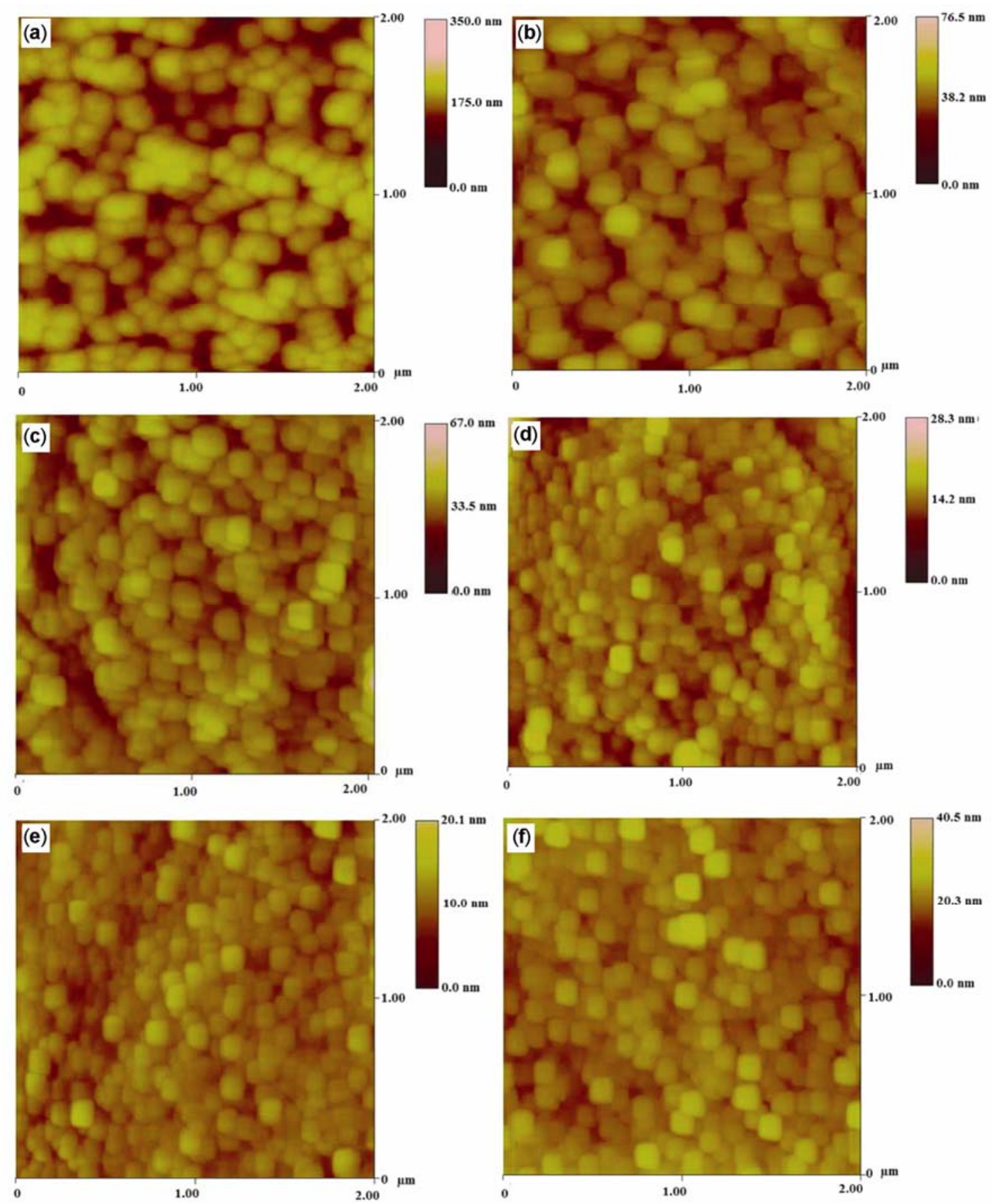

Figure 2. AFM micrographs of IZO films at (a) $0 \%$, (b) $1 \%$, (c) $2 \%$, , d) $3 \%$, (e) $4 \%$ and (f) $5 \%$. 

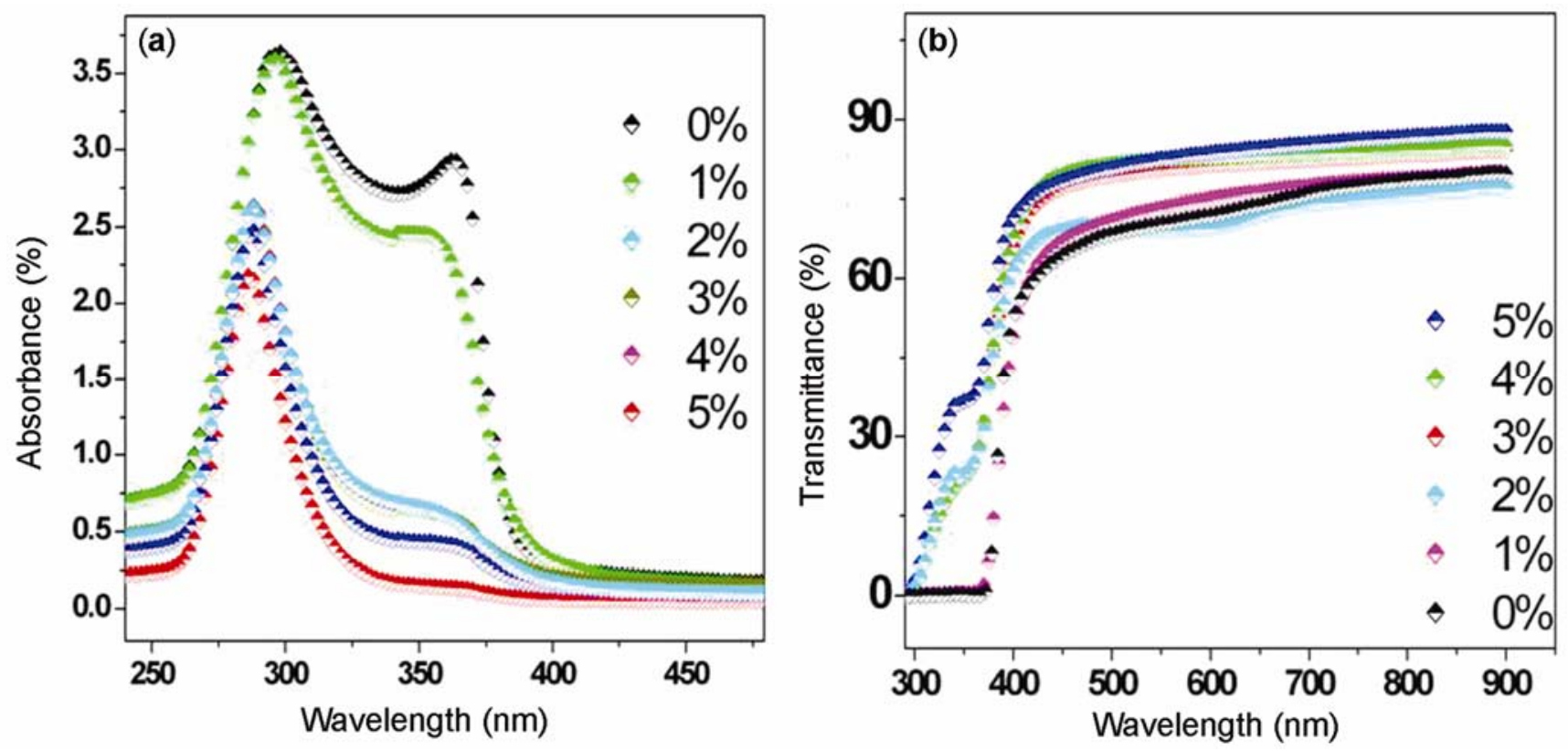

Figure 3. (a) Optical absorbance spectra and (b) optical transmittance spectra of IZO films.

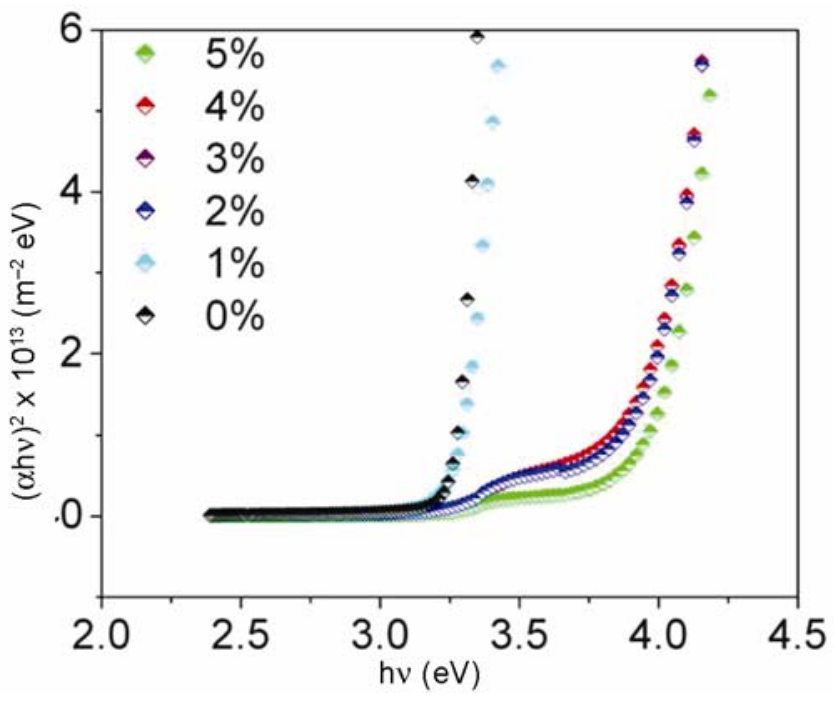

Figure 4. Variation of $(\alpha h v)^{2}$ vs $h v$ curve for IZO films.

the indium dopant percentage. The increase in the lattice parameter must be caused by interstitial incorporation of indium ions into the lattice. It is reported that indium atom takes interstitial site rather than replacing zinc sites thereby deforming the lattice. Chen et al (2006) also reported the same results for development in the $C$ parameter by Li doping.

\section{Morphological studies}

Figure $2(\mathrm{a}-\mathrm{f})$ shows the AFM of IZO deposited at $380^{\circ} \mathrm{C}$ on glass substrate with different indium dopant concentrations. The micrograph shows uniform polycrystalline nature of the IZO films. Undoped $\mathrm{ZnO}$ film has a uniform surface morphology with many voids. When a small amount of indium (1\%) was doped, numbers of voids are found to decrease. The particle size and roughness of IZO are found to decrease with the indium doping percentage. In addition the density of the features increases as the doping concentration increases. The AFM image (figure $2 \mathrm{~b})$, corresponding to the lowest IZO (1\%) exhibits grains of size $156.36 \mathrm{~nm}$ (calculated from the statistical distribution curve). As the indium content increases, the grain size decreases, the lowest grain size has been obtained for $5 \%$ IZO film, i.e. $112.23 \mathrm{~nm}$. This reveals that doping with indium leads to the formation of the films with bigger smoothness or we can say that the indium atoms distributed uniformly in $\mathrm{ZnO}$ film making an orderly arrangement.

\section{Optical studies}

The absorbance spectra of IZO in the UV-Vis region are shown in figure 3(a). From the figure it is clear that there was no optical absorption in the visible region. However, the UV region of the absorbance versus wavelength curve shows a split peak for undoped and lightly indium doped $\mathrm{ZnO}$ films. This may be due to the fact that the $\mathrm{Zn}^{+2}$ with $d$ electron energy level could be split by the effect of the crystal field, resulting in the split peak in the UV spectrum (Rathneesh Kumar et al 2005). Beyond the absorption edge figure was not symmetric for the undoped and lightly indium doped film. This could be related to the oxygen and metal charge transfer. The energy at which charge transfer occurs between oxygen and metals depends on the cations and the symmetry of its coordi- 

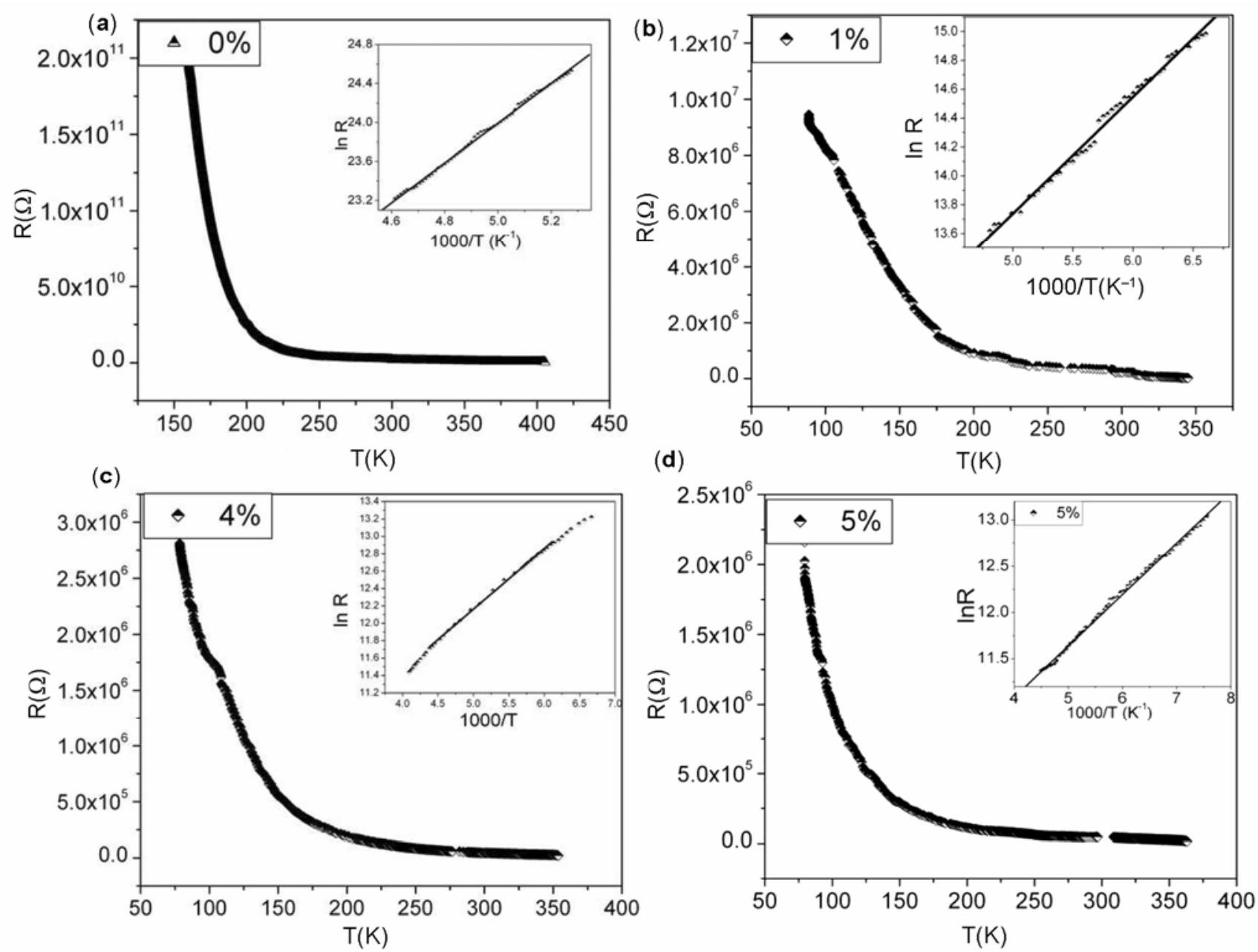

Figure 5. Temperature vs resistance curve for IZO films.

nate site (Lin et al 2004). As the indium doping increases, the figure was found to be more symmetric. Thus we can say that for lightly doped film there is less charge transfer, while at higher doping better charge transfer is seen between oxygen and zinc. Symmetry of the absorption spectrum could be related to the transfer of electron to the conduction band and hence to the variation in resistivity. Optical transmittance spectra (figure 3(b)) of IZO show excellent transmittance $(>80 \%)$ and a sharp cut off between 360 and $375 \mathrm{~nm}$. It is clear from the transmittance spectra that increment in doping percentage slightly affects the transmittance of the film. This might be due to the formation of grainy surface leading to large scattering loss. The optical bandgap $\left(E_{\mathrm{g}}\right)$ of the thin films could be obtained by plotting $(\alpha h v)^{2}$ vs $h v$ curve ( $\alpha$ is the absorption coefficient and $h v$ the photon energy) and extrapolating the straight-line portion of this plot to the energy axis as shown in figure 4 . The absorption coefficient ' $\alpha$ ' has been calculated using Lambert's law for directly allowed transition for simple parabolic scheme as a function of incident photon energy as (Ables 1992):

$$
\alpha h v \propto\left(h v-E_{\mathrm{g}}\right)^{1 / 2}
$$

where $E_{\mathrm{g}}$ is the optical band. The values of optical bandgap so obtained are listed in table 1 . As can be seen from the figure that initially up to $2 \%$ In doping $E_{\mathrm{g}}$ value increases drastically and then at higher doping it remains nearly constant. This large shift in optical bandgap is mainly due to Burstein moss effect, which states that in semiconductor as we increase the doping concentration the lowest state in the conduction band is blocked which is responsible for the widening in the optical bandgap. This shift is caused by a charge carrier density increase, which is presumably the reason for the measured resistivity decrease with doping concentration. At higher doping small widening in $E_{\mathrm{g}}$ value might be due to low crystallinity.

\section{Electrical studies}

The resistivity measurement of the above prepared films has been done by using conventional four probe resistivity method at various dopant concentrations. The results so obtained are shown in figure $5(\mathrm{a}-\mathrm{d})$. From the figure it 
is clear that resistance decreases as the temperature increases showing the semiconducting behaviour of $\mathrm{ZnO}$. The activation energy $\left(E_{\mathrm{a}}\right)$ corresponding to the films prepared at various In dopant concentrations are calculated by using Arrhenius equation which are plotted in figure 6 . A look at the figure reveals that activation energy shows decreasing trend with the increase in indium doping percentage. The resistivity values are listed in table 1. At room temperature resistivity values were found to decrease from $2.8 \times 10^{3}$ to $0.045(\Omega-\mathrm{m})$ as the indium doping percentage increases from 0 to $5 \%$. This trend can be understood from the fact that the number of electrons increases owing to the formation of many electrons. This suggests that the number of oxygen vacancies decreases because indium ions combine with the oxygen more strongly thereby reducing oxygen vacancies scattering with electron, the resistivity decreases (Pankove 1965). At lower doping concentration electrons from the dopant play a dominant role in the film and as less oxygen vacancy scattering occurs, the resistivity decreases. However, at higher doping percentage $(\sim 4 \%, 5 \%)$, the grain size becomes smaller and numerous grain boundaries formed. Consequently grain boundary scattering disturbs electron movement. So there is no large decrease in resistivity with higher indium doping concentrations.

\section{Conclusions}

IZO films have been deposited at various dopant concentrations on glass substrate by CSPT. The samples are $\left(\begin{array}{lll}0 & 0 & 2\end{array}\right)$ preferentially oriented, although orientations became lower as the In concentration increased implying that doping with indium leads to the introduction of defects in the $\mathrm{ZnO}$ crystals. This indicates changes in the lattice symmetry and loss of crystalline quality of films.

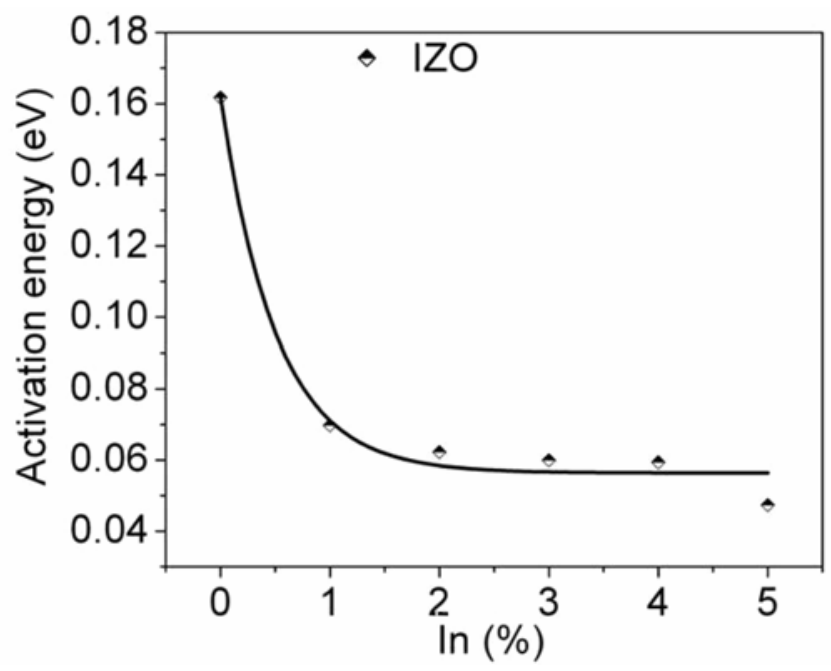

Figure 6. Activation energy of IZO films as a function of In doping.
The AFM micrograph reveals that the film deposited at lower dopant concentrations has well defined grains, however, high dopant concentration lead to a more uniform and smoother surface. The minimum electrical resistivity values of the order of $0.045(\Omega-\mathrm{m})$ were obtained for the film deposited with $5 \%$ indium dopant concentrations. The optical transmittance and absorption band edge are found to increase as the indium dopant concentration increased. While at higher doping it is nearly constant. Bandgap values are found in the interval of $3 \cdot 26-3.95 \mathrm{eV}$ for the film reported in this work. So, we may conclude that the present method of preparation has resulted into an optimum IZO film with good crystallinity, structural, optical and electrical characteristics.

\section{Acknowledgements}

The authors would like to thank Director, Centre Director and staff of UGC-DAE CSR, Indore centre, for support and encouragement, Dr Manoj Rathore, Mr L S Sharath Chandra, Dr P N Vishwakarma, Ms S Pandya, Ms Niitu Badera and Mr Mohan Gangrade for their help. One of the authors (GS) would like to acknowledge MPCST, Bhopal, for providing financial assistance under the FTYS programme.

\section{References}

Ables A 1992 Optical properties of solids (Amsterdam: North Holland) p. 32

Assuncao V, Fortunato E, Marques A, Aguas H, Ferreira I, Costa ME V and Martins R 2003 Thin Solid Films 427 401

Ataev B M, Bagamadova A M, Djabrailov A M, Mamedo V V and Rabadanov R A 1995 Thin Solid Films 26019

Ataev B M, Bagamadova A M, Mamedov V V, Omaev A K and Rabadanov M R 1999 J. Cryst. Growth 198-199 1222

Barret C S and Massalski T B 1980 Structure of metals (Oxford: Pergamon Press)

Cao Y, Miao L, Tanemura S, Tanemura M, Kuno Y, Hayashi Y and Mori Y 2006 Jpn J. Appl. Phys. 451623

Cembrero J, Elmanouni A, Hartiti B, Mollar M and Marí B 2004 Thin Solid Films 198451

Chen L L, He H P, Ye Z Z, Zeng Y J, Lu J G, Zhao B H and Zhu L P 2006 Chem. Phys. Lett. 420358

Chen M, Pei Z, Xi W, Sun C and Wen L 2001 Mater. Res. Soc. Symp. Proc. 666 F.1.2

Godbole B, Badera N, Shrivastava S B, Ganesan V and Jain D 2007 Surf. Rev. \& Letts 141

Goyal D J, Agashe C, Takwale M G, Bhide V G and Mahamuni Kulkarni S K 1993 J. Mater. Res. 81052

Kato H, Sano M, Miyamoto K and Yao T 2002 J. Cryst. Growth 538237

Kim Dong Hun, Cho Nam Gyu and Kim Ho Gi 2007 J. Electrochem. Soc. 154 H939

Ko H J, Chen Y F, Hong S K, Wenisch H, Yao T and Look D C 2000 Appl. Phys. Lett. 773761 
Lee J -H and Park B -O 2004 Mater. Sci. Eng. B106 242

Lee J H, Ko K H and Park B O 2003 J. Cryst. Growth 247119

Lin S -S, Huang J -L and Lii D -F 2004 Surf. Coat. Technol. 176173

Liu Z F, Shan F K, Li Y X, Shin B C and Yu Y S 2003 J. Cryst. Growth 259130

Ma J Y and Lee S C 2000 J. Mater. Sci., Mater. Electron. 1135

Major S, Banerjee A, Chopra K L and Nagpal K C 1986 Thin Solid Films 14319

Miki-Yoshida M, Paraguay-Delgado F, Estrada-Lopez W and Andrade E 2000 Thin Solid Films 37699

Minami T, Nanto H and Takata S 1984 Jpn J. Appl. Phys. 23 L280
Myong S Y, Baik S J, Lee C H, Cho W Y and Lim K S 1997 Jpn J. Appl. Phys. 36 L1078

Ozgur U, Alivov Ya L, Liu C, Teke A, Reshchikov M K, Dogan S, Ayrutin V, Cho S -J and Morkoc H 2005 J. Appl. Phys. 98 041301

Pankove J I 1965 Phys. Rev. 140 A2059

Rathneesh Kumar P M, Kartha C S, Vijayakumar K P, Abe T, Kashiwaba Y, Singh F and Awasthi D K 2005 Semicond. Sci. Technol. 20120

Singh A V, Kumar M, Mehra R M, Wakanaria A and Yoshida A 2001 J. Indian Inst. Sci. 81527

Song D, Denborg PW, Chin W and Aberle A G 2002 Sol. Energy Mater. Sol. Cells 731 